\title{
CO-DESIGN TO SELF-ORGANIZING EXERGAMING - A STUDY OF STIMULATING PHYSICAL ACTIVITY FOR ELDERLY PEOPLE WITH A CHRONIC HEALTH CONDITION
}

\author{
Linda Askenäs ${ }^{1}$, Jan Aidemark ${ }^{1}$, Tiny Jaarsma ${ }^{2}$, Anna Sttrömberg ${ }^{2}$ and Leonie Klompstra ${ }^{2}$ \\ ${ }^{1}$ Linnaeus University, Växjö, Sweden \\ ${ }^{2}$ Linköpings University, Norrköping, Sweden
}

\begin{abstract}
Life expectancy is increasing and physical activity has been shown to be an effective to improve outcomes for patients with chronic conditions. However, there are a lot of barriers that make elderly people with chronic disease not being physical active. The purpose of this study is to explore the potential of using co-design as a method to implement physical activity in a social context for elderly organizations. With the aim to explore exergaming in a social setting, a co-design process was conducted using the experience-based design theory. The study also relied on studies using gaming as exercise method for heart failure patients. The method was participative observations that was documented as a storytelling. The project contained a number of key co-design actions; engaging users early; using the competition element; engaging patient organization and bringing the design into an existing social context; focus on self-organizing, not as a plan more focus an emerging property that may appear; practical testing element in the design made it possible to understand the multiple views of motivational factors. The project should allow for and encourage a multifaceted outcome, as this would reach and satisfy broader layers of people.
\end{abstract}

\section{KEYWORDS}

E-health, Exergaming, Co-design, Self-organizing, Chronic Disease

\section{INTRODUCTION}

Life expectancy is increasing, and there is a growing proportion of elderly people with one out of three developing a chronic condition. (Chatterji et al, 2015) Physical activity has been shown to be effective in improving outcomes for patients with chronic conditions (Chatterji et al, 2015). However, there are a great number of barriers (for example pain, costs and fear of injury) that constitute a risk that elderly people with a chronic disease are not physical active. Exergames show a potential as a physical activity or rehabilitation tool for older adults (Skjæret et al, 2016, Molina et al, 2014 and Klompstra et al, 2014). Exergaming seems to be safe and enjoyable to elderly people, especially when done in a social context (Skjæret et al, 2016, Molina et al, 2014, Klompstra et al, 2014, Klompsta et al 2017 and Radhakrishnan et al, 2018). An exergame is defined as 'the playing of video games that requires rigorous physical exercise, that is intended as a work-out and during which the participant moves large muscle groups in the arms, legs, core, or neck in response to cues (Gao et al, 2016).

Adherence to physical activity among the elderly is low and it has been shown that the peer-mentoring model has the potential to be a cost-effective method for reaching out to older adults engaging them in physical exercise programs for extended periods and improving their health and fitness (Sander and Stappers, 2008). To explore the social context of exergaming in elderly people with chronic health conditions, co-design could be a method for achieving sustainable physical activity.

In this paper we wish to explore the potential of using co-design as a method for how to implement physical activity in a social context in organizations for the elderly. Co-design as a process of information system development aims at transferring the focus from the technology towards the user. One stated aim of using co-design is to move the user to the center of an information system development project (Norman, 2009). 
A core theme in this strategy of user centricity is user empowerment and the transfer of decision-making power to the user. Among the challenges of achieving this, a number of problems have been identified, for example the level of expertise of the user in various respects. Another problem for a successful co-design is the (intended) user's motivation for participating. In the area of E-health, these problems appear to constitute a complex process involving many communities (different care units, patients, relatives, patient organizations etc.) (Aidemark et al, 2015), in comparison with any other form of information system development process (e.g. commercial or company-based). There are many answers to why a user, who in e-health cases is often a patient, chooses to take part. These reasons may include a clear interest in the particular problem, an IT interest, general curiosity, or a strong wish to contribute to and improve care processes (Dorgo, 2009). More peripheral reasons are likely, such as being social and saying yes when asked, or wanting to be part of a group. There might also be attractive rewards or a pure individual desire to improve a personal situation by taking part. A development process must provide clear and strong motivating forces for the users and empower them to be active participators in the co-design process. In other words, it is not only the intent and actions of the developers that are important, it also a question of what drives the participating users.

\section{PROJECT METHOD}

With the aim to explore exergaming in a social setting, a co-design process was started. This process was initiated by contacting two neighboring located patient organizations. They were asked if they would like to start exergaming and set up a tournament between the two organizations. The chairmen of both organizations were positive and invited members to join the co-design process. There were about 4-8 participants from each organization in the meetings, consisting of both female and male elderly persons with heart-related conditions, in the 66-85 age group. The data collection method included participative observations of focus group meetings and more practice-related exergaming events. The researchers set up the agenda for the focus group meetings entailing that the practice of exergaming was self-managed in the two organizations and observed by the researchers. The findings were recorded in the form of storytelling of what happened based on field notes and other documentation. The stories were then analyzed in different dimensions, primarily concerning the aims of motivation, the empowerment and the outcome in comparison with the co-design process.

\section{PROJECT FINDINGS}

The project focuses on using exergaming a key self-care advice to stimulate elderly persons with chronic health conditions to engage in more physical activities. This process was designed to construct a concept for exergaming bowling for elderly with this health problem. The approach was to work with patient advocacy groups from this area of diagnosis (heart failure). These groups are already engaged in activating their members by offering work-out sessions or providing advice. The technology used in the project was standard gaming consoles and games with no principal IT development involved. However, the system properties of applying the technology were subject to a co-design process with the focus on getting people to build up habits around the technology. Functional technology is one aspect, while people taking action by using the technology is another. Generally, long-term and sustained usage outside trial periods is a challenge.

A co-design process was started with the aim of creating a systemic way of working with exergaming that could motive a long-term organic use of console-based games for physical activity. The project would provide a trial period, which would be transformed into a self-sustaining activity (Jaarsma et al, 2015). The task given to the co-design team was to design a process of bowling training and competition using Wii or X-box consoles. The result of the co-design process is then expected to be adopted as a working model in real settings, i.e., as a self-sustained activity outside a research context.

This process consisted of set of meetings and workshops creating an environment for the project. A relatively open process in five stages was envisioned: 
- Stage 1. Pre-planning

- Stage 2. Setting up co-design groups

- $\quad$ Stage 3. Initial testing and design of exergaming concepts

- Stage 4. Testing design ideas and bowling training

- Stage 5. Implementation of design outcome and bowling competition.

Stage 1) The project was initiated by a patient engaged in a heart failure support organization. In this first stage, the patient organization representative, who had previously participated in a Wii-training study (Jaarsma et al, 2015), pushed for a renewed Wii bowling project by involving researchers from different disciplines. The researchers agreed on an overall plan for co-designing a competition with two local organizations providing support for heart failure patients. All the researchers then practiced exergaming and set up different ways of how to arrange this competition. Aspects discussed in this initial plan included technology, choice of game, online-game competition, onsite competition (gaming in the same physical location), having a web-page for presenting the results, how to compete (teams of 2-4 or of couples, or grandchildren for instance.). There were a number of different design principles that needed to be decided on whether to include in the co-design.

In this manner, the co-design process started with a number of internal design meetings, providing principal decisions on matters like the direction and purpose of the process and its expected outcomes. Representatives of the patient groups were involved in these meetings.

Stage 2) Getting people to participate is a cumbersome task depending on individuals with a strong will and clear visions. To increase the interest in the project, the idea of organizing the exergaming in the form of bowling competitions was introduced along with the results of former research projects. The two chairmen of the local organizations were introduced to the idea. One of them had extensive experience of exergaming and also a good understanding of the importance of stimulating exercise for elderly people with a chronic health condition. It was also viewed as a way of making better use of the already existing facilities (such as localities by adding consoles for gaming which could be used by many people. The other chairman was highly reluctant but was persuaded to take part in the process. People from the user community were recruited on the basis of their willingness to take part and be drivers of the creative process. Five persons were recruited from the first organization and one from the second to take part in the next stage.

Stage 3) All the participants met up at the same location and were introduced to each other and to the idea behind the project. The technology was presented, in this case both the commercially available "Wii-U" and "X-box One" bowling games were tested. There were different opinions of what console was preferred and how the competition between the two neighboring towns should take place. The participants tested both consoles and most of them chose to play bowling. After this meeting, the more reluctant chairman that was part of the session was convinced that this could be a good idea, not only for heart failure patients, but also for other elderly people. He became so inspired that he asked for setting up four lanes (sets of consoles with bowling games) in their sport hall facilities, which are shared among different patient organizations. The other chairman bought a new TV set to make it possible for members to play bowling. The group of five patients in Organization 1 started to practice. They sent inspiring, triggering photos to the other team, tried to recruit more members and also asked the research team to set up a webpage to show their records. In the other team, they were somewhat more reluctant due to their internal problems with decreasing membership.
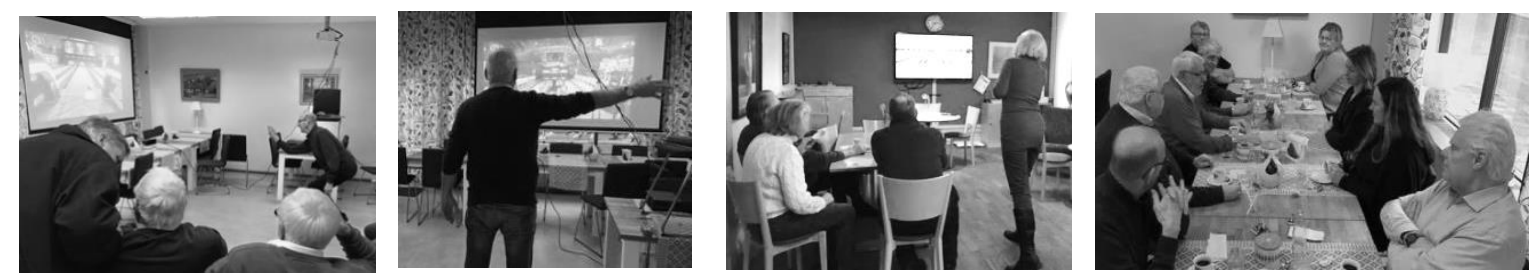

Figure 1. Stage 3. Co-designing and testing by gaming

Stage 4) In the fourth stage, an invitation was sent to all current members of the two organizations to take part in training sessions. Learning to play bowling with Wii or Xbox was offered, and the idea of having team competitions was introduced. The purpose of the meetings was to include the design of the competition and the forming of teams. New members were recruited and, in Organization 2, 5 new members showed up in the practice sessions. The development in Organization 1was negative, since out of the first group of 5 people only 
4 continued and it was hard to find new members. Regular gaming sessions were arranged. The groups practiced 4-6 times with participants of different levels. The training became more of a self-organizing activity for the user/co-design groups. Teams now started to form and training sessions were scheduled by the team members. This became a self-driving process, which gave the design team more opportunities to watch. The project thus turned into an activity with some degree of autonomy. There were differences in people's view of the training, with some being enthusiastic while others who did not find it very engaging only wished to take part in the competition. There was a certain amount of rivalry and competitive spirit between the two cities that fueled the interest in the bowling project.

Stage 5) In the last stage, a final competition was tried out with the two teams involved. One team visited the other town's team and two different games were set up. To begin with, the researchers gave information on different studies and on the benefit of using/practicing exergaming as a physical activity. There were discussions about how to get more people involved locally, including suggestions that this should also be set up at nursing homes. After the discussion, the competition started, whereby the two teams split up into new groups consisting of members from both teams. One group decided not to run a competition-based setting, but rather just play together, as some of its members felt that they were not good enough. The other team started a competition round by playing two games with two against two, with one team winning the first time and the other the next time. The latter group wanted to take part in a rematch at the other location later in the spring.

Thus, there was great individual difference with regard to the vision of a competition. Some wanted to get together and compete among themselves, in order to improve, while others were more inspired to compete in teams against the other town's team. They also had different opinions on which game they preferred. This implies that the final design will need to offer multiple ways of running the tournaments and the practice.

\section{SELF-ORGANIZING A CO-DESIGN PROCESS}

This dimension of the process is directed towards the empowerment aspect of co-design and forms an example of users' actual decision-making. The blending of the design process into a regular activity of an organization is of course looked upon as a great step forward for the design team, as it will be a long-term goal of the project. The project's clear intention of having a distinct user focus could be seen as an element in this development. The choice of technology, i.e., standard consoles, paves the way for this outcome. To focus on the users and matters like the ease of use and the availability of the technology instead of trying to invent a new type of gaming technology, was part of the design philosophy. This could be seen as an example of how co-design becomes co-creation. The involvement of the chairmen in the actual design process and also the strong intention to create an understanding of how this design could become a sustainable activity which was also possible to transfer to other local organization gave the participants the freedom to act on their own. Besides, the researchers' authority in telling them that using exergaming with the aim to become physical active has been proved to be good self-care behavior made the action easier and more motivated. This could be compared to findings of self-organizing from complex theory (Coleman, 1999), where the elements of freedom to act - empowerment, with a clear attributer driving the innovation - like a knowledge of former projects (research) supporting self-care activates and side-effects (socially engaging members socially, the use of facilities) and agents that could realize the innovation (available technology, budget and members). Moving beyond the initial stage requires clearly stated opportunities and benefits for the participants (Chertow, and Ehrenfeld 2012), and the organizing also needs to meet their different needs. 


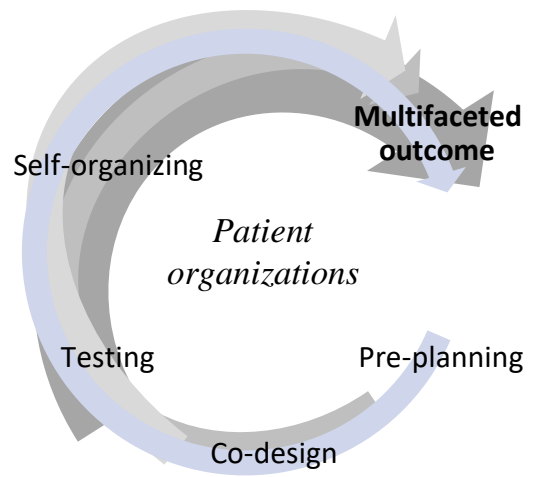

Figure 2. The co-design process more than just co-designing

The project contained a number of key co-design actions, as illustrated in Figure 2:

(1) Engaging users early on to ensure the validity of the project. In this case, the initiative came from a key person, which became the start of-the pre-planning phase.

(2) Using the competition element to draw the attention away from exercising for health to competitive interaction with people from a neighboring city. Focusing on competing as a part of gaming seemed to be a motivating factor but by allowing different views of whether to compete or just being social was a success factor.

(3) Engaging patient organizations, including the design in an existing social context and thereby ensuring relevance and lending a degree of importance to the project. This could also be a key to achieving sustainability for the exergaming effort.

(4) The self-organizing element, which is not looked upon as a planned action of the co-design but rather an emerging property that appears organically.

(5) The practical testing element in the design made it possible to understand the multiple views of motivational factors, where the end result showed different design criteria of how to compete, e.g. whether to create a social or a competitive dimension to gaming. The project should allow for and encourage a multifaceted outcome, as this would reach and satisfy broader layers of people.

\section{DISCUSSION AND CONCLUSION}

Co-design in the field of eHealth needs further development, where the balance between the major stakeholders is explored and more elaborate processes are defined. To promote episodes of user self-organization could be an element that creates possibilities for the actual implementation and sustainability of the design/solutions. Incorporating prolonged test periods into the co-design for all stakeholders/users may also develop new and multifaceted design criteria. In Figure 3 we illustrate this by comparing the degree of both self-organizing and practical testing. The degree of self-organizing concerns the level of autonomy of the team members, resulting in changes in the solutions or how to use them. This takes place without a formal design agreement in the co-design process and hence changes the organizational circumstances of the co-design. The degree of practical testing concerns how truly different designs are tested and compared in everyday living and practice. 


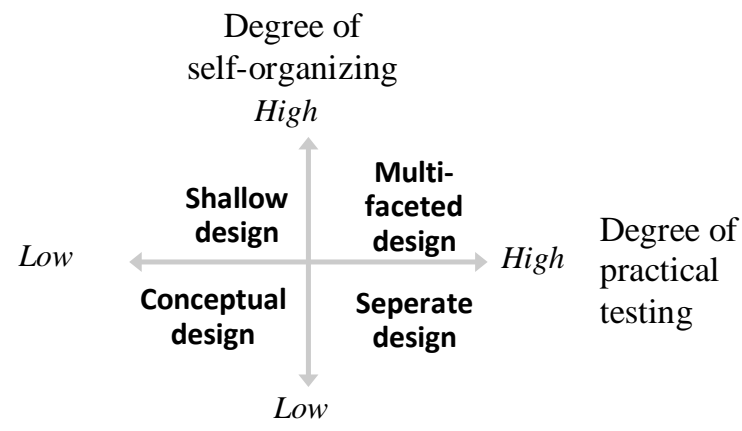

Figure 3. Dimensions of co-design affecting the outcome design

Conceptual design: A low degree in both dimensions requires a more theoretical design that is neither tested in practice nor self-organized in the institution/social context. In this case it would affect the result of the first stage, where the researchers view the competition on a wii console game while having a webpage to share the results.

Shallow design: With a low degree of testing but a high degree of self-organizing, the design runs a great risk of being rather shallow, where opportunities or quick decision-making will guide the implemented design, e.g. in this case by buying a TV set.

Separated design: With a low degree of self-organizing but a high degree of practical testing there may be a great risk of ending up with designs that are not anchored in the organization or are too narrow and focused on specific user-oriented aspects separated from the organization as a whole, e.g. when the exergaming in one of the teams is practiced in other circumstances.

Multi-faceted design: A high degree in both dimensions would make it possible to achieve a multifaceted design that is both partly integrated and understood in the organization and at the same time contains different design criteria as in this case where both social and competitive gaming possibilities were to be integrated in the final design.

However, such a perspective on co-design methods should be applied in a broader framework and empirical settings concerning the understanding of co-design. For example, the differences between co-design processes in a science project and in organizational development projects should also be considered.

\section{ACKNOWLEDGEMENT}

This work is supported through the Swedish National Science Council (K2013-69X-22302-01-3, 2016-01390), Swedish National Science Council/Swedish research council for health, working life and welfare (VR-FORTE) 2014-4100, The Swedish Heart and Lung Association E085/12, The Swedish Heart-Lung Foundation (20130340 and 20160439), the Vardal Foundation (2014-0018), the Medical Research Council of Southeast Sweden (FORSS 474681).

\section{REFERENCES}

Aidemark, J., Askenäs, L., Nygårdh A. and Strömberg, A., 2015. User involvement in the co-design of self-care support systems for heart failure patients. Procedia Computer Science" Vol. 64, pp.118 - 124.

Chatterji, Somnath et al. 2015. Health, functioning, and disability in older adults - present status and future implications. The Lancet, 385.9967, pp. 563-575.

Chertow, M. Ehrenfeld, J. 2012. Organizing Self-Organizing Systems. Journal of Industrial Ecology, Vol. 16 pp. 13-27.

Coleman, Jr. H. J. 1999. What Enables Self-Organizing Behavior in Businesses, Emergence Vol.1 No.1, pp. 33-48.

Dorgo, S., King, G.A. and Brickey, G.D. 2009. The application of peer mentoring to improve fitness in older adults. J Aging Phys Activ. Vol.17 pp. 344-361. 
Gao Z., Lee JE., Pope Z., and Zhang D., 2016 Effect of active videogames on underserved children's classroom behaviors, effort, and fitness. Games Health Journal, Vol.5, pp.318-324.

Jaarsma, Tiny, Klompstra, L., Ben Gal, T., Boyne, J., Vellone, E., Bäck, M., „, Strömberg, A. 2015. Increasing exercise capacity and quality of life of patients with heart failure through Wii gaming: the rationale, design and methodology of the HF-Wii study; a multicentre randomized controlled trial. European journal of heart failure, Vol. 17 No. 7 , pp. 743-748.

Klompstra, L., Jaarsma, T. and Strömberg A. 2014. Exergaming in older adults: A scoping review and implementation potential for patients with heart failure.” European Journal of Cardiovascular Nursing, Vol. 13 No. 5, pp. 388-398.

Klompstra, L. Jaarsma, T. Mårtensson, J., Strömberg, A., and Verheijden. 2017. Exergaming Through the Eyes of Patients with Heart Failure: A Qualitative Content Analysis Study." Games for Health Journal, Vol. 6, No. 3, pp. 152-158.

Molina, K., Ricci, N., De Moraes, S., \& Perracini, M. 2014. Virtual reality using games for improving physical functioning in older adults: a systematic review. Journal of Neuroengineering and Rehabilitation, Vol. 11, No.1, pp. 156.

Norman, C. D. 2009. Health promotion as a systems science and practice. Journal of Evaluation in Clinical Practice, Vol. 15. pp. 868-872.

Sander EB-N Stappers JP. 2008. Co-creation and the new landscapes of design. International Journal of Cocreation in Design and the Arts. Vol. 4, No. 1, pp. 5-18.

Skjæret, N. Nawaz, A. Morat, T. Schoene, D. Helbostad, J.L. and Vereijken. B. 2016. Exercise and rehabilitation delivered through exergames in older adults: An integrative review of technologies, safety and efficacy." International Journal of Medical Informatics Vol. 85, No. 1, pp. 1-16. 